\title{
Mechanical properties of Hybrid steel/PVA fiber reinforced high strength concrete
}

\author{
Wasim Abbass ${ }^{1}$ and M. Iqbal Khan, ${ }^{2, *}$ \\ ${ }^{1}$ Assistant Professor, Department of Civil Engineering, UET, Lahore, Pakistan \\ ${ }^{2}$ Professor, Department of Civil Engineering, King Saud University, Riyadh, Saudi Arabia
}

\begin{abstract}
The high strength concrete exhibits improved compressive strength with drawback of brittle failure due to lack of tensile strength which can be catered by the addition of fibers. The efficient use of fibers with hybridization at macro and micro level can improve mechanical properties of high strength concrete. The effect of hybridization of hooked end steel macro fibers $(60 \mathrm{~mm})$ and PVA micro fibers $(12 \mathrm{~mm})$ with different dosages was investigated in this research work. The different percentage of steel and PVA were hybridized to find out the best combination of hybridized fibers in high strength concrete. The compressive and flexural properties of high strength concrete along with complete load vs deflection behaviour of hybrid fiber reinforced concrete were investigated. The results revealed that hybridization of macro and micro fibers provided better improvement in flexural performance. It was observed from the results that the hybrid combination of fibers of $1 \%$ macro steel fiber and $0.15 \%$ micro PVA fibers proved to be the best for enhancement in flexural performance of high strength concrete.
\end{abstract}

\section{Introduction}

Concrete technology is evolving with the passage of time and bringing smart materials in construction to achieve sustainable structures. Fiber reinforced concrete is advanced material with improved tensile properties of concrete by arresting cracks with the use of short random fibers [1]. Increased toughness, increased strength, improved ductility of material, and hardening behaviour in post cracking response as compared to that of plain concrete are major characteristics enhanced with addition of fibers [2, 3]. High strength concrete with addition of mono fibers i.e. steel or synthetic has shown improvement in tensile properties in concrete [4]. The technique of combining the different type of fibers to achieve their maximum efficiency in the concrete is known as hybridization. This optimization process of different fibers for positive interaction between the fibers is commonly termed as "synergy". Different researcher have made a lot effort to identify synergy by optimizing the fiber ratio [5-10]. Optimization of fiber for synergetic effect for flexural and direct tension are reported $[11,12]$. Whereas, in some of the cases, there was no synergetic effect was observed due to influence of matrix and in some cases synergy was found under certain loading such as shear [13]. Different type of fibers were added high strength concrete to achieve improved mechanical and durability related properties $[14,15]$. This research work presented herein is focused on finding the synergy of different fibers (steel and PVA) in terms of compressive strength, flexural strength, displacement capacity. Hooked end steel macro fibers and PVA micro fibers are combined to different percentage ratio to maximum of $1 \%$ steel fibers and $0.25 \%$ PVA fibers in concrete by volume fraction and their effect on the mechanical properties of high performance concrete is investigated.

\section{Materials and Methods}

\subsection{Cement}

Ordinary Portland cement (OPC), ASTM Type I, locally available cement was used. The chemical composition of the cement is shown in Table 1.

Table 1. Chemical composition of cement.

\begin{tabular}{|c|c|}
\hline $\mathrm{SiO}_{2}$ & $20.2 \%$ \\
\hline $\mathrm{Al}_{2} \mathrm{O}_{3}$ & $5.49 \%$ \\
\hline $\mathrm{Fe}_{2} \mathrm{O}_{3}$ & $4.12 \%$ \\
\hline $\mathrm{CaO}$ & $62.43 \%$ \\
\hline $\mathrm{MgO}$ & $0.71 \%$ \\
\hline $\mathrm{SO}_{3}$ & $2.61 \%$ \\
\hline $\mathrm{Na}_{2} \mathrm{Oeq}$ & $0.26 \%$ \\
\hline Loss on ignition & $1.38 \%$ \\
\hline Specific gravity & 3.14 \\
\hline Fineness $\mathrm{m}^{2} / \mathrm{kg}$ & 373 \\
\hline
\end{tabular}

\footnotetext{
* Corresponding author: miqbal@ksu.edu.sa
} 


\subsection{Admixture}

High-range water-reducing (HRWR) modified polycarboxylate based super plasticizer conforming to the requirements of ASTM C494 type F was used.

\subsection{Fine and Coarse Aggregates}

Two different sands with different particle sizes and fineness moduli of 1.47 and 4.66 were mixed to achieve fineness modulus of 2.54. Coarse aggregate of maximum size of $10 \mathrm{~mm}$ was used for the preparation of concrete mixtures.

\subsection{Fibers}

Two different type of fibers 1 . hooked ended macro steel fibers and 2. PVA micro fibers were used in this study. The tensile strength and Young's modulus of the used steel fibers were $1250 \mathrm{MPa}$, and $210 \mathrm{GPa}$ respectively. The tensile strength and Young's modulus of the used PVA fibers were $1300 \mathrm{MPa}$, and $38 \mathrm{GPa}$ respectively. Other properties of the used steel fibers are summarized in Table 2 .

Table 2. Properties of hook ended steel and PVA fiber.

\begin{tabular}{|c|c|c|c|}
\hline & $\begin{array}{c}\text { Length } \\
(\mathrm{mm})\end{array}$ & $\begin{array}{c}\text { Diameter } \\
(\mathrm{mm})\end{array}$ & $\begin{array}{c}\text { Aspect ratio } \\
(\mathrm{l} / \mathrm{d})\end{array}$ \\
\hline PVA & 12 & 0.04 & 300 \\
\hline Steel & 60 & 0.75 & 80 \\
\hline
\end{tabular}

Total five different concrete mixes with different combination of two fibers (steel and PVA) were prepared. In the mix design, water/cementitious ratio of 0.30 and the slump of $150 \pm 25 \mathrm{~mm}$ were chosen for concrete without fibers. Fibers with two different lengths $60 \mathrm{~mm}$ (macro steel) and $12 \mathrm{~mm}$ (micro PVA) with two different diameters (0.75 and 0.04$)$ were used in the mixes. Mixes were designated as $0.75+0.25$, where 0.75 represents percentage of steel fiber and 0.25 represents percentage content of PVA fiber. The quantities for each mix are presented in Table 3.

All aggregates (coarse and fine) were added to the mixer and absorption water were added with some revolution followed by addition of cement with dry mixing for few minutes. Premixed superplasticizer with water was added to concrete mixture. All the materials were mixed for three minutes followed by rest of three minutes and then again mixing for two minutes. Mixer was stopped and samples were cast for plain concrete. For fiber reinforced concrete, fibers were added to concrete followed by mixing of concrete until good dispersion of fiber in the concrete was achieved.

Concrete cylinder specimens of $100 \times 200 \mathrm{~mm}$ were cast for standard compressive strength test in rigid plastic molds. Specimens of $75 \times 75 \times 300 \mathrm{~mm}$ were prepared for the flexural strength of fiber reinforced concrete. Flexural specimens were casted in two layers and vibration was done for 15-20 seconds for each layer. The top surface of the specimen was smoothened with trowel and the specimens were covered with plastic sheet to maintain moist condition. The specimens were demolded after 24 hours and cured under $100 \%$ relative humidity at temperature of $22 \pm 2{ }^{\circ} \mathrm{C}$ until the age of testing.

Compressive strength of concrete was measured by using cylinder of $100 \times 200$ under Tonitech compression testing machine and flexural specimen were tested using INSTRON model 3367 at a loading rate of $0.2 \mathrm{~mm} / \mathrm{min}$ for recording the post peak behaviour of fiber reinforced concrete as shown in Figure 1. Ductility or energy absorption capacity of the mixtures was calculated by area under load deflection curve until maximum peak load.

Table 3. Mix proportions for all mixes.

\begin{tabular}{|c|c|c|c|c|c|c|}
\hline Description of Mix & $\begin{array}{c}0.75+ \\
0.25\end{array}$ & $\begin{array}{c}0.85+ \\
0.15\end{array}$ & 1.0 & $\begin{array}{c}1.0+ \\
0.15\end{array}$ & $\begin{array}{c}1.0+ \\
0.25\end{array}$ & Cont. \\
\hline $\mathrm{kg} / \mathrm{m}^{3}$ & $\mathrm{~kg} / \mathrm{m}^{3}$ & $\mathrm{~kg} / \mathrm{m}^{3}$ & $\mathrm{~kg} / \mathrm{m}^{3}$ & $\mathrm{~kg} / \mathrm{m}^{3}$ & $\mathrm{~kg} / \mathrm{m}^{3}$ \\
\hline Cement (OPC) & 500 & 500 & 500 & 500 & 500 & 500 \\
\hline Steel Fibers (Macro) & 58.8 & 66.7 & 78.5 & 78.5 & 78.5 & 0.0 \\
\hline PVA Fibers (Micro) & 3.25 & 1.95 & 0.0 & 1.95 & 3.25 & 0.0 \\
\hline Aggregate 10mm & 1052 & 1052 & 1052 & 1052 & 1052 & 1052 \\
\hline Sand (Crushed sand) & 251 & 251 & 251 & 251 & 251 & 251 \\
\hline Sand (White sand) & 467 & 467 & 467 & 467 & 467 & 467 \\
\hline water & 164 & 164 & 164 & 164 & 164 & 164 \\
\hline
\end{tabular}



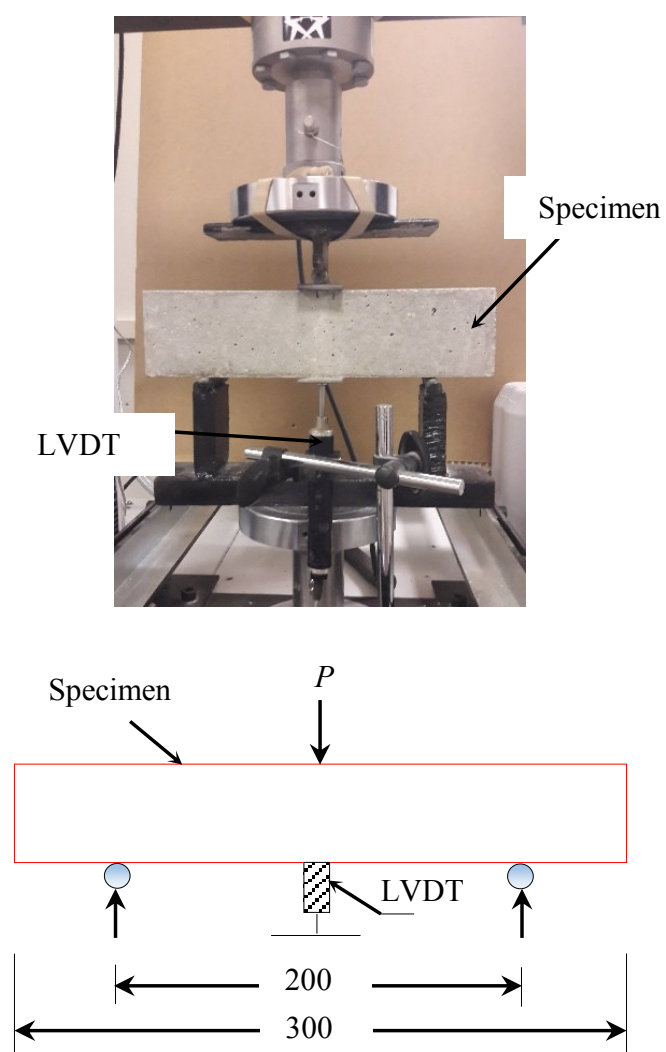

Note. All dimensions are in $\mathrm{mm}$

Fig. 1. 3-Point flexural test setup and schematic diagram for concrete and SHCC specimens.

\section{Results and discussion}

The results for the compression test conducted for plain concrete, hybrid macro steel and micro PVA fiber reinforced concrete with different percentage combinations are presented in Figure 2. There was increase in compressive strength with increase in content of addition of macro steel fibers in high strength concrete with respect to control mixture. It can be observed from the Figure 2 that with the increase in dosage of macro steel fibers in the concrete, the compressive strength has increased up to $8 \%$ for $1 \%$ dosages of macro steel fibers and $0.15 \%$ micro PVA fibers. There is almost no decrease or compromise on most of the dosages of hybrid macro steel fibers and micro PVA fibers in high strength concrete. This may be attribute to the facts, i). Steel fibers has arrested the macro cracks and delaying failure of concrete, ii). Increased number of steel fibers in the plain concrete has increased anchorage of matrix and fiber with increased interlock of concrete matrix with steel fibers.

The flexural strength results obtained from three point loading using set up are presented in Figure 3 . The results are described as flexural strength for different content of macro steel fibers and micro PVA fibers at age of 28 days is shown in Figure 3. The increase in the flexural strength for different addition of fiber content is shown in Figure 3.

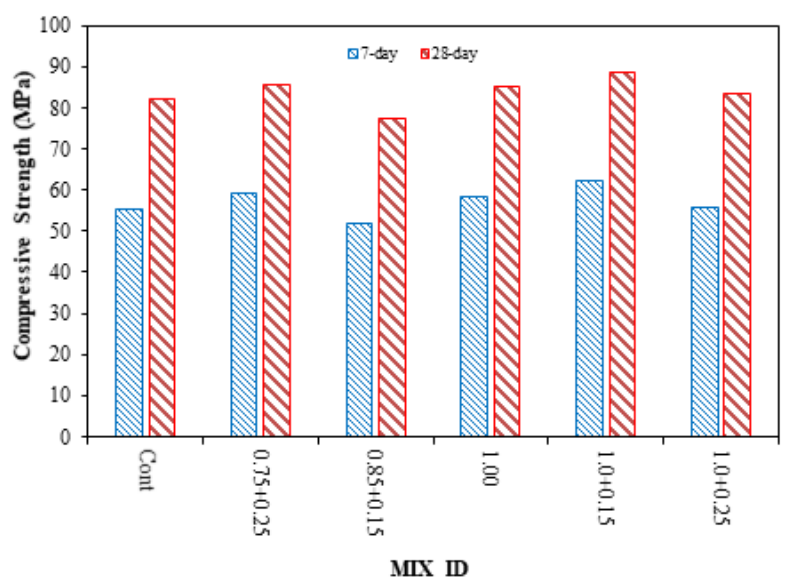

Fig. 2. Compressive strength of hybrid fiber reinforced concrete.

It can be observed that increase in the flexural strength of mixture with increased steel fiber content has reached to almost $200 \%$ with the addition of $1 \%$ of macro steel fibers and $0.15 \%$ micro PVA fibers as compare to plain concrete. The addition of $1 \%$ of macro steel fibers in the concrete has increased the flexural strength up to $150 \%$ with respect to plain concrete. This may be attribute to the fact that it delays crack formation and arrest crack to increase failure load of the concrete mixture with steel fibers. Fiber bridging stress has increased the deflection behaviour of fiber reinforced concrete giving more flexural strength than plain concrete.

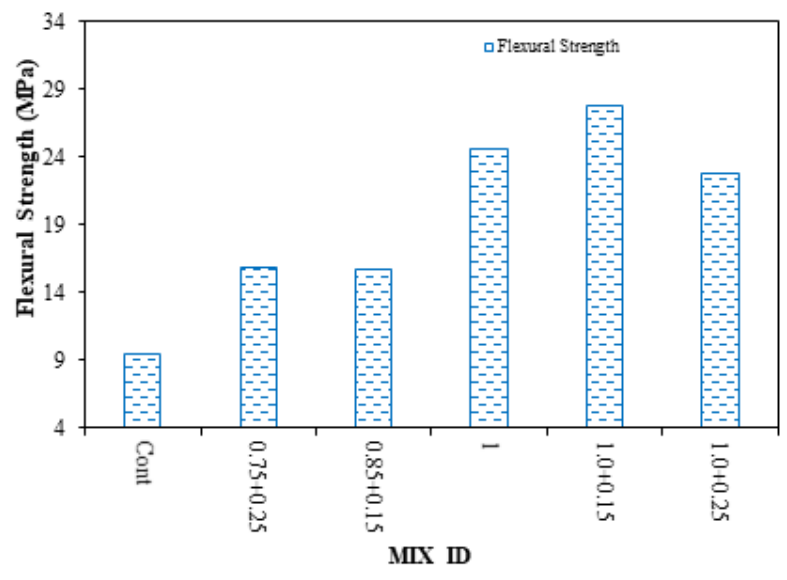

Fig. 3. Flexural strength of hybrid fiber reinforced concrete.

The load vs deflection behaviour of steel fiber reinforced concrete using mono and hybrid steel fibers is shown in Figure 4. It can be observed from the result that peak flexural stress does not coincide with the first crack stress, which occurred earlier on the load deflection curves of all the mixture, therefore composite exhibits this behaviour can be named deflection hardening of steel fiber reinforced mixture [16].

The load vs deflection response of concrete with and without fibers is shown in Figure 4. The addition of macro steel fibers and micro synthetic fibers has shown deflection hardening behaviour of concrete mixtures. It can be clearly observed from the Figure 4 that plain concrete has shown sudden failure whereas the addition 
of fibers in the concrete has increase the peak load after first crack of concrete. There is clear indication of deflection hardening behaviour of hybrid fiber reinforced concrete using macro steel fibers in combination with micro synthetic fibers. There was gain in load after first crack of concrete mixture with fibers in all the concrete mixtures with different dosages of fiber combinations showing deflection hardening behaviour. It was observed that the increase in dosage of macro steel fiber has significantly improved the post peak behaviour of concrete mixture with hybrid steel and micro PVA fibers as shown in Figure 4.

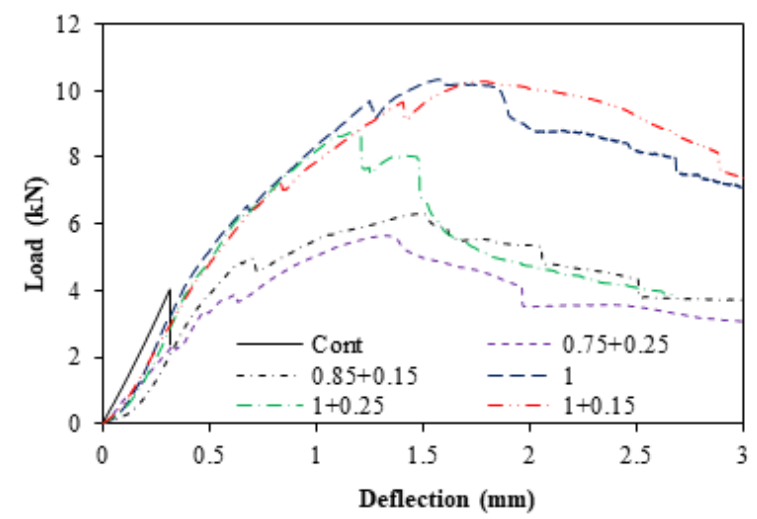

Fig. 4. Load vs deflection response of hybrid steel fiber reinforced concrete.

Figure 5 shows the energy absorption capacity of concrete with different hybridization of steel/synthetic fibers. The hybrid composite mixture have shown increased toughness and energy absorption capacity with different combinations of steel and synthetic fibers. It can be observed from the Figure 5 that hybrid fiber of content ( $1 \%$ steel fiber and $0.15 \%$ PVA fiber) has shown synergetic effect in terms of energy absorption capacity. Energy absorption capacity of different mixtures have been calculated until the maximum load. Optimum content of fibers ( $1 \%$ steel fibers and $0.15 \%$ PVA fibers $)$ was observed on the basis of energy absorption capacity.

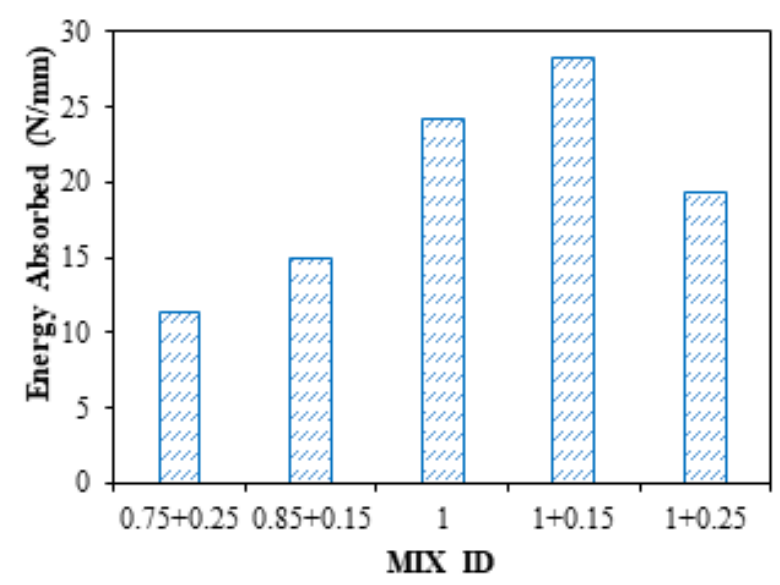

Fig. 5. Ductility of hybrid fiber reinforced concrete.

\section{Conclusions}

Properties of plain and hybrid fiber reinforced concrete with steel and PVA fibers have been examined in this paper under compression and flexural tests. Hybridization of fibers was done on the different volumetric ratio of steel and PVA fibers for concrete mixture. Following results can be concluded based on the experimental observation:

The maximum increase in compressive strength of 2$8 \%$ was observed with the addition of hybrid fibers to plain high strength concrete. There is no significant effect of hybridization of compressive strength of concrete.

Peak bending stress and ultimate deflection increased due to the addition of hybrid fibers and even better flexural performance was observed using hybrid fibers. An increase in the flexural strength of mixture with fibers reached up to $150-200 \%$ with the variation of combination of hybrid fibers as compare to that of plain concrete.

Hybrid fiber of content ( $1 \%$ steel fiber and $0.15 \%$ PVA fiber) has shown synergetic effect in terms of energy absorption capacity and ductility.

\section{References}

1. A. Bentur, S. Mindess, Fiber Reinforced Cementitious Composites, Taylor and Francis (2007)

2. P.N Balaguru, S.P. Shah, Fiber Reinforced Cement Composites, McGraw Hill, New York (1992)

3. G. Fischer, V.C. Li, Eng. Fract. Mech., 74, 258-272, (2007)

4. W. Abbass, M.I. Khan, S. Mourad, Constr. Build. Mater., 168, 556-569, (2018).

5. N. Banthia, M. Sappakittipakorn, Cem. Conc. Res., 37(9), 1366-1372, (2007)

6. A. Bentur, S. Mindess, Fiber Reinforced Cementitious Composites, Elsevier Applied Science, London (1990)

7. G. Xu, S. Magnani, D.J. Hannant, Cem. Conc. Comp., 20(1), 79-84, (1998)

8. N. Kistaiah, C.U. Kiran, G.R. Reddy, M.S.,Rao, J. Reinf. Plast. Compos. (2014)

9. L.G. Sorelli, A. Meda, G.A. Plizzari, ASCE J. Mater. Civ. Eng. 17 (1), 519-527, (2005)

10. L. Cominoli, A. Meda, G.A. Plizzari, In: Adv. Constr. Mater., Springer Science-Business Media (2007)

11. Y. Mohammadi, S.P. Singh, S.K. Kaushik, Constr. Build. Mater. 22(5), 956-965, (2008)

12. N. Banthia, S.M. Soleimani, ACI Mater. J., 102(6), 382-389, (2005)

13. E.B. Pereira, G. Fischer, J.A.O. Barros, Cem. Conc. Comp., 34(10), 1114-1123, (2012)

14. V. Afroughsabet, T. Ozbakkaloglu, Constr. Build. Mater., 94, 73-82, (2015) 
15. M.Cao, L. Li, M. Khan, Mater. De Constr., 68(330), (2018)

16. N. Banthia, F. Majdzadeh, J. Wu, V. Bindiganavile, Cem. Conc. Comp., 48, 91-97, (2014) 